\section{Examination of Phosphoryl-Mimicking Functionalities within a Macrocyclic Grb2 SH2 Domain-Binding Platform}

Sang-Uk Kang, ${ }^{\dagger}$ Zhen-Dan Shi, ${ }^{\dagger}$ Karen M. Worthy, Lakshman K. Bindu,

Pathirage G. Dharmawardana, ${ }^{\S}$ Sarah J. Choyke, ${ }^{\S}$

Donald P. Bottaro,$^{\S}$ Robert J. Fisher, ${ }^{\ddagger}$ and

Terrence R. Burke, Jr.*,†

Laboratory of Medicinal Chemistry, Center for Cancer Research, National Cancer Institute, National Institutes of Health, Frederick, Maryland 21702, Protein Chemistry Laboratory, SAIC-Frederick, Frederick, Maryland 21702, and Urology Oncologic Branch, Center for Cancer Research, National Cancer Institute, National Institutes of Health, Bethesda, Maryland 20892

Received January 20, 2005

Abstract: Reported herein are the design, synthesis, and Grb2 SH2 domain-binding affinities of several phosphorylmimicking groups displayed within the context of a conformationally constrained macrocyclic platform. With use of surface plasmon resonance techniques, single-digit nanomolar affinities were exhibited by phosphonic acid and malonyl-containing diacidic phosphoryl mimetics (for $\mathbf{4 h}$ and $\mathbf{4 g}, K_{\mathrm{D}}=1.47$ and $3.62 \mathrm{nM}$, respectively). Analogues containing monoacidic phosphoryl mimetics provided affinities of $K_{\mathrm{D}}=16-67 \mathrm{nM}$. Neutral phosphoryl-mimicking groups did not show appreciable binding.

SH2 domain-binding antagonists have been developed by a number of groups as potential alternatives to kinase inhibitors. ${ }^{1-4}$ Despite their central roles in SH2 domain recognition processes, phosphotyrosyl residues (pTyr, 1, Figure 1) are contraindicated as components of such inhibitors because of their hydrolytic lability and the poor cellular bioavailability of the doubly ionized phosphoryl moiety. Replacement of the phosphoryl ester oxygen with either $-\mathrm{CH}_{2}-$ or $-\mathrm{CF}_{2}-$ has yielded hydrolytically stable analogues such as Pmp (2) and $\mathrm{F}_{2} \mathrm{Pmp}(\mathbf{3})$, respectively. However the anionic charge of these phosphonate-based structures still presents problematic issues of bioavailability. Therefore, phosphoryl mimetics continue to be sought that retain high binding affinity, yet exhibit reduced net anionic charge. ${ }^{5,6}$

To date, monoacidic phosphoryl mimetics have tended to exhibit less affinity than diacidic mimetics. ${ }^{7,8}$ This can be attributed in part to the presence of two highly conserved positively charged Arg residues within the SH2 domain pTyr binding pocket. ${ }^{9}$ If one role served by pTyr binding is to promote capture of conformationally flexible peptides from solution and thereby allow secondary ordering of the peptide along the protein surface, the importance of interactions within the pTyrbinding pocket may be diminished for ligands whose solution conformations are preordered for binding. This could be reflected in a reduced requirement for diacidic

* To whom correspondence should be addressed. Phone: (301) 846-5906. Fax: (301) 846-6033. E-mail: tburke@helix.nih.gov.

Laboratory of Medicinal Chemistry, National Cancer Institute.

¥ SAIC-Frederick.

$\S$ Urology Oncologic Branch, National Cancer Institute.

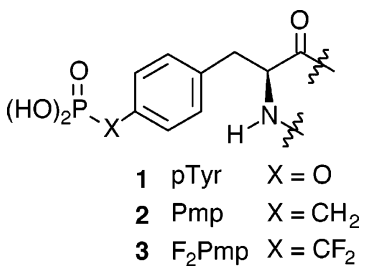

Figure 1. Structures of pTyr and pTyr mimeitcs.

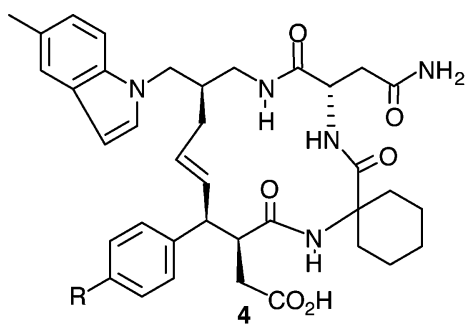
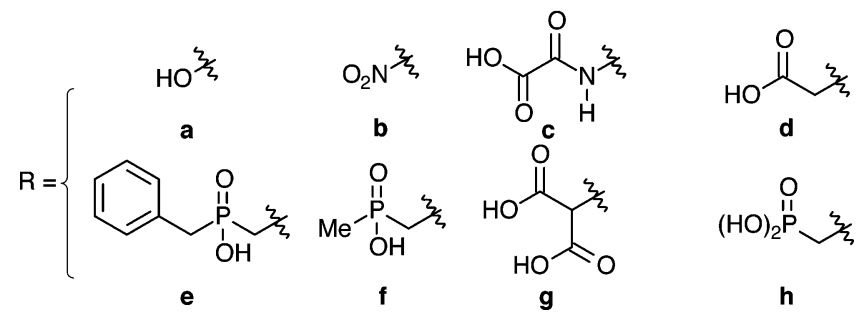

Figure 2. Structures of macrocyclic Grb2 SH2 domainbinding antagonists.

phosphoryl-mimicking charge for certain conformationally constrained ligands.

Recently, a series of macrocyclic peptide mimetics typified by $\mathbf{4 h}$ have been reported that bind to Grb2 SH2 domains with extremely rapid on-rates (Figure 2). ${ }^{10,11}$ The high $k_{\text {on }}$ values may indicate that solution conformations are preordered for binding. Therefore, macrocycles such as 4 may provide qualitatively different platforms for investigating phosphoryl mimicking functionality than afforded by conventional nonconstrained peptides. Since the 5-methylindolyl-containing 4 has only been reported bearing a diacidic phosphonic acidbased phosphoryl mimetic (4h), the current study was undertaken to use this platform to examine additional diacidic (4g), monoacidic (4c-f), and neutral $(\mathbf{4 a}, \mathbf{b})$ phosphoryl mimetics.

All analogues were prepared as shown in Scheme 1. A characteristic feature of macrocycle construction was the use of protected $\beta$-vinyl-containing $\mathrm{pTyr}$ mimetics $\mathbf{1 0},{ }^{12}$ which was coupled to the 5-methylindolyl-containing dipeptide $\mathbf{1 1}^{11}$ to yield metathesis precursors 12 . The synthesis of $10 \mathrm{~g}$ has been reported previously. ${ }^{13}$ Ring closure of 12 using second-generation Grubbs' catalyst $\left.\left[\left(\left(\mathrm{PCy}_{3}\right)\left(\operatorname{Im}(\mathrm{Mes})_{2}\right) \mathrm{Ru}=\mathrm{CHPh}\right)(\mathbf{1 1})\right)\right]^{14,15}$ provided the protected macrocycles 14, which were converted to the final products 4 by treatment with acid. In the case of $\mathrm{N}$-oxalyl-containing $\mathbf{4 c}$, the nitro-containing precursor 14b was first reduced to the corresponding amine using freshly prepared $\mathrm{Al}-\mathrm{Hg}$ amalgam, then reacted directly with tert-butyl oxalyl chloride $/{ }^{2} \mathrm{Pr}_{2} \mathrm{NEt}$ to give the protected amide 15c, which was converted to $\mathbf{4 c}$ by treatment with TFA (Scheme 2). The carboxymethyl ana- 
Scheme 1

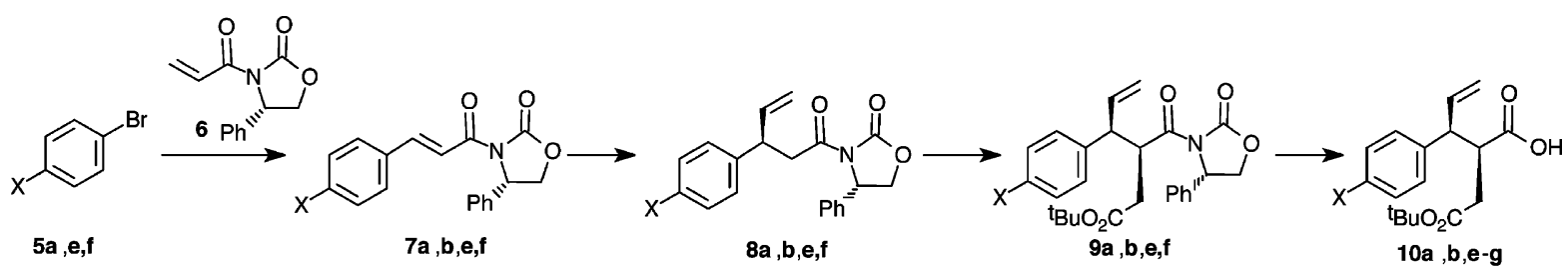<smiles>C=CCC(CNC(=O)[C@H](CC(N)=O)NC(=O)C1(N)CCCCC1)Cn1ccc2cc(C)ccc21</smiles><smiles>[X]c1ccc(C(CC=C)C(CC(C)OC(C)=O)C(=O)NC2(C(=O)N[C@@H](CC(N)=O)C(=O)NCC(CC=C)Cn3ccc4cc(C)ccc43)CCCCC2)cc1</smiles>

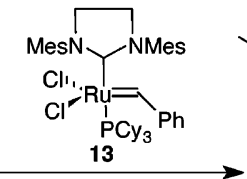

$12 a, b, e-g$

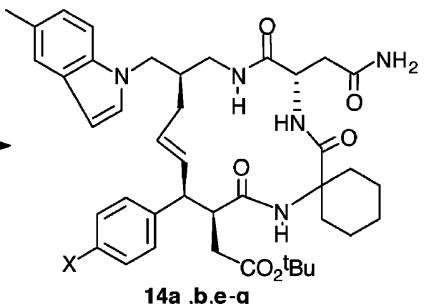

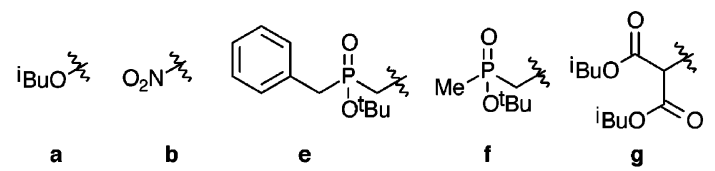

\section{Scheme 2}

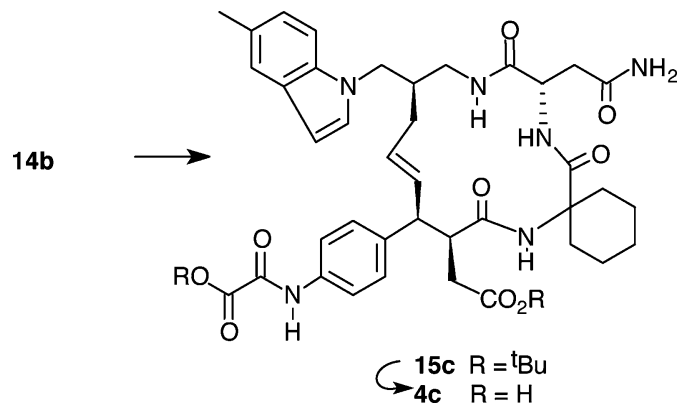

logue $\mathbf{4 d}$ was obtained by lithium hydroxide mediated decarboxylation of $\mathbf{4 g}$.

Preparation of the key $\beta$-vinyl-containing $\mathrm{pTyr}$ mimetics 10 proceeded from the $\alpha, \beta$-unsaturated oxazolidinone-containing $\mathbf{7}^{16}$ through $\mathbf{8}$ by initial 1,4 -addition of vinylmagnesium bromide ${ }^{17}$ followed by conversion to 9 using stereoselective alkylation with $\alpha$-bromo tertbutyl acetate. ${ }^{12}$ With the exception of the nitro-containing $\mathbf{7 b}$, construction of intermediates $\mathbf{7}$ was by Heck reaction of 4-substituted phenylbromides (5) with known (S)- $N$-acroyl-4-phenyl-2-oxazolidinone (6). ${ }^{17}$ The corresponding Heck reaction of 4-bromonitrobenzene failed. However the desired nitro-containing $\mathbf{7 b}$ can be obtained by condensation of commercially available 4-nitrocinnamic acid with the Evans auxiliary $(S)$-4-phenyl-2oxazolidinone.

Starting aryl bromide $\mathbf{5} \mathbf{a}^{18}$ was obtained by reaction of 4-bromophenol with tert-butyl 2,2,2-trichloroacetimidate $/ \mathrm{BF}_{3} \cdot \mathrm{Et}_{2} \mathrm{O}$. For the synthesis of starting tertbutyl phosphinate 5e, ammonium phosphinate was first prepared by careful addition of $50 \%$ aqueous hypophosphorus acid to an equal-molar quantity of aqueous ammonia at $0{ }^{\circ} \mathrm{C}$. This was stirred for $1 \mathrm{~h}$ at room temperature and then lyophilized to provide a hygroscopic white solid, which was dried over $\mathrm{P}_{2} \mathrm{O}_{5}$ under high vacuum. The freshly prepared ammonium phosphinate was converted to bis(trimethylsilyl)phosphonite by heat- ing under argon with hexamethyl disilazane under argon. [Caution: vapors are flammable.] This was then reacted with benzyl bromide, followed by a second treatment with hexamethyl disilazane. Alkylation with 4-bromobenzyl bromide gave (4-bromobenzyl)benzylphosphinic acid, which was converted to 5 e by esterification with tert-butyl 2,2,2-trichloroacetimidate/BF ${ }_{3} \cdot \mathrm{Et}_{2} \cdot{ }^{19,20}$ The corresponding tert-butyl (4-bromobenzyl)methylphosphinate $\mathbf{5 f}$ was prepared in a similar fashion by sequential treatment of bis(trimethylsilyl)phosphonite with 4-bromobenzyl bromide, then hexamethyl disilazane, then methyl iodide, and finally, tert-butyl 2,2,2trichloroacetimidate/ $\mathrm{BF}_{3} \cdot \mathrm{Et}_{2}$.

Evaluation of binding affinity to recombinant Grb2 SH2 domain protein was accomplished using an enzyme linked immunosorbent assay (ELISA) based competition assay $^{21,22}$ and a surface plasmon resonance (SPR) assay that provided real-time kinetic data, including $k_{\text {on }}$ and $k_{\text {off values (Table } 1) .}{ }^{23,24}$ On the basis of SPR data, the highest affinities were exhibited by diacidic phosphoryl mimetic-containing $\mathbf{4} \mathbf{g}$ and $\mathbf{4 h},{ }^{25,26}$ which showed enhanced binding on-rates $\left(k_{\mathrm{a}}\right)$ that were more than 5 -fold greater than analogues having fewer acidic groups. The highest affinity among the monoacidic phosphoryl mimetics was shown by the methylphosphinic acid 4f, which had twice the affinity of the benzylphosphinic acid $\mathbf{4 e}$ or the carboxymethyl analogue $\mathbf{4 d}$. The oxalylamido analogue 4c showed the poorest affinity among the monoacidic phosphoryl mimetics because of a disproportionately rapid off-rate $\left(k_{\mathrm{d}}\right)$. Compounds with uncharged phosphoryl mimetics (4a and 4b) showed little affinity (up to $1000 \mathrm{nM}$ ). ELISA-based IC $_{50}$ values for $\mathbf{4 d}$ and $\mathbf{4 g}$ were in close agreement with SPR-derived $k_{\mathrm{D}}$ values. However, $\mathbf{4 c , e , f}$ gave lower $\mathrm{IC}_{50}$ values than would be expected on the basis of SPR data, while $\mathbf{4 h}$ gave a higher $\mathrm{IC}_{50}$ value. The reasons for these differences are not known. However, the ELISA IC $_{50}$ values are more dependent on experimental conditions than 
Table 1. Grb2 SH2 Domain-Binding Results

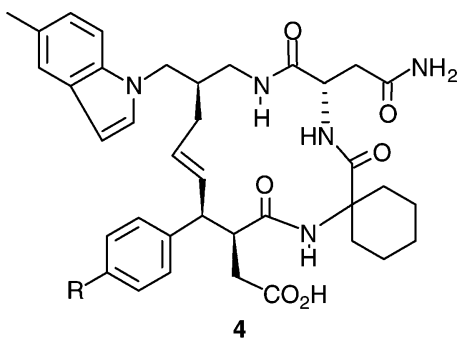

\begin{tabular}{|c|c|c|c|c|c|c|c|}
\hline No. & R Group & $k_{a}\left(M^{-1} s^{-1}\right)^{a}$ & $k_{\mathrm{d}}\left(s^{-1}\right)^{a}$ & $K_{D}+/-$ S.E. (nM & 1) & \multicolumn{2}{|c|}{$\mathrm{IC}_{50}+/-$ S.E. (nM) ${ }^{\mathrm{b}}$} \\
\hline $4 a$ & $\mathrm{HO}^{\frac{3}{2}}$ & - & - & $>1000$ & $(n=2)$ & - & \\
\hline $4 b$ & $\mathrm{O}_{2} \mathrm{~N}^{\xi}$ & - & - & $>1000$ & $(n=2)$ & - & \\
\hline $4 c$ & & $8.66 \times 10^{5}+/-6.25 \times 10^{3}$ & $5.08 \times 10^{-2}+/-2.14 \times 10^{-4}$ & $67+/-0.1$ & $(n=6)$ & $8.8+/-3.0$ & $(n=3)$ \\
\hline $4 d$ & & $3.06 \times 10^{5}+/-1.20 \times 10^{3}$ & $1.01 \times 10^{-2}+/-2.25 \times 10^{-5}$ & $33.0+/-0.1$ & $(n=4)$ & $22.5+/-4.7$ & $(n=3)$ \\
\hline $4 e$ & & $1.45 \times 10^{5}+/-2.45 \times 10^{2}$ & $5.12 \times 10^{-3}+/-8.65 \times 10^{-6}$ & $35.3+/-0.1$ & $(n=6)$ & $8.4+/-0.7$ & $(\mathrm{n}=3)$ \\
\hline $4 f$ & & $6.09 \times 10^{5}+/-1.47 \times 10^{3}$ & $9.88 \times 10^{-3}+/-1.11 \times 10^{-5}$ & $16.2+/-0.01$ & $(n=4)$ & $6.3+/-2.0$ & $(n=1)$ \\
\hline $\mathbf{4 g}$ & & $6.27 \times 10^{6}+/-3.09 \times 10^{4}$ & $2.27 \times 10^{-2}+/-3.86 \times 10^{-5}$ & $3.62+/-0.02$ & $(n=6)$ & $3.3+/-0.3$ & $(n=3)$ \\
\hline $4 \mathrm{~h}$ & $\mathrm{HO}_{1}^{\mathrm{NO}} \mathrm{PH}_{\mathrm{OH}}$ & $5.46 \times 10^{6}+/-3.66 \times 10^{4}$ & $8.01 \times 10^{-3}+/-4.40 \times 10^{-5}$ & $1.47+/-0.01^{c}$ & $(n=6)$ & $15.0+/-8.0$ & $(n=1)$ \\
\hline
\end{tabular}

${ }^{a}$ Obtained by SPR experiments as described in ref 23 , where " $n$ " refers to the number of surfaces fit to a global analysis of a simple Langmuir binding isotherm and where the errors in $k_{\mathrm{a}}$ and $k_{\mathrm{d}}$ reflect the error of the global fit to these paramenters. $K_{\mathrm{D}}$ and associated $\mathrm{SE}$ values were calculated as described in ref 24 , with the SE values also being the errors of the global analysis. ${ }^{b}$ Obtained by ELISA-based experiments as described in ref 22, wherein $\mathrm{IC}_{50}$ values \pm the standard error of the mean (SE) were obtained as the mean of " $n$ " independent experiments performed with nine doses per curve with each dose done in quadruplicate. ${ }^{c}$ Value as reported in ref 25.

the SPR-derived $K_{\mathrm{D}}$ values, and the SPR data should be used as the more reliable indicator of binding affinity.

Significant effort has been directed toward reducing phosphoryl-mimicking charge on SH2 domain binding antagonists. For example, on the basis of a phosphatecontaining $556^{\text {lck }} \mathrm{SH} 2$ domain-binding dipeptide mimetic $\left(K_{\mathrm{D}}=40 \mathrm{nM}\right)$, a group from Boehringer Ingelheim Pharmaceuticals obtained low micromolar $K_{\mathrm{D}}$ values using several monoacidic phosphoryl mimetics, including carboxymethyl and oxalylamido-based analogues. ${ }^{8}$ In our own hands, open-chain analogues containing monocarboxy-based pTyr mimetics have been shown to exhibit Grb2 SH2 domain $\mathrm{IC}_{50}$ values in the low micromolar to submiromolar range. ${ }^{7}$ Novartis Corporation has reported low micromolar to submicromolar affinity constants for monoacidic phosphinic acid based pTyr mimetics that include benzyl and methyl phosphinates upon which analogues $\mathbf{4 e}$ and $\mathbf{4 f}$ of the current study were predicated. ${ }^{27}$ In all of these prior reports, affinities of inhibitors bearing monoacidic phosphoryl mimetics were in the submicromolar range at best. Accordingly, to our knowledge, $4 \mathbf{f}$ is the most potent Grb2 SH2 domain-binding antagonist yet reported having a monoacidic phosphoryl mimetic.

In the interpretation of these results, care should be taken in equating the number of acidic groups contained in a phosphoryl mimetic with formal charge, since complete ionization may not occur at a given $\mathrm{pH}$. For example, it is known that because of elevated $\mathrm{p} K_{\mathrm{a} 2}$ values, bis-acidic phosphonic acids are only partially ionized at neutral $\mathrm{pH}$, in contrast to phosphoryl groups, which are di-ionized at $\mathrm{pH} 7 .{ }^{28}$ Differences in ionization states between phosphoryl groups and phosphonic acids have been used to at least partially explain reduction in SH2 domain-binding affinity often observed when the pTyr phosphate group is replaced with a phosphonic acid moiety. ${ }^{29}$ Additionally, factors other than anionic charge, such as hydrogen-bonding acceptor/donor properties, may contribute to variations in affinity exhibited by different phosphoryl mimetics.

It is of note that although large losses of affinity are observed for $\mathbf{4 a}$ and $\mathbf{4 b}$, which lack any phosphorylmimicking acidic groups, only modest losses of affinity occurred for monoacidic phosphoryl mimetics (i.e., a 
10-fold reduction for $\mathbf{4 f}$ compared to $\mathbf{4 h}$ ). This may be attributed to the differential roles in pTyr recognition played by the $\operatorname{Arg} \beta B 5$ residue, which is situated in the rear of the binding pocket compared to the more anteriorly located Arg $\alpha \mathrm{A} 2$ residue. Thermodynamic studies have shown that while the $\operatorname{Arg} \beta \mathrm{B} 5$ residue is critical for recognition and binding of pTyr-containing peptides, the Arg $\alpha \mathrm{A} 2$ residue is less important. ${ }^{30}$ Data presented in Table 1 highlight the need for high-affinity binding of at least one anionic interaction with the $\operatorname{Arg} \beta \mathrm{B} 5$ residue. It is of note that cyclic Grb2 $\mathrm{SH} 2$ domain-binding peptides have been reported that are devoid of phosphate-mimicking functionality at the $\mathrm{Y}^{0}$ position. However, these peptides contain acidic residues at the Y-2 amino acid position that are hypothesized to bond with the $\operatorname{Arg} \beta B$ B5 residue, thereby highlighting the importance of this critical interaction. ${ }^{31}$

In conclusion, by examination of a variety of phosphoryl mimicking functionalities within the context of a conformationally constrained Grb2 SH2 domainbinding platform, ligands have been identified that contain monoacidic phosphoryl mimetics that exhibit low nanomolar affinities. The current study may facilitate the development of therapeutically relevant Grb2 SH2 domain-binding antagonists.

Supporting Information Available: Detailed experimental procedures for the preparation of final products $4 \mathbf{a}-\mathbf{g}$ and results from elemental analysis. This material is available free of charge via the Internet at http://pubs.acs.org.

\section{References}

(1) Pawson, T.; Gish, G. D.; Nash, P. SH2 domains, interaction modules and cellular wiring. Trends Cell Biol. 2001, 11, 504511

(2) Shakespeare, W. C. SH2 domain inhibition: a problem solved? Curr. Opin. Chem. Biol. 2001, 5, 409-415.

(3) Muller, G. Peptidomimetic SH2 domain antagonists for targeting signal transduction. Top. Curr. Chem. 2001, 211, 17-59.

(4) Feller, S. M.; Tuchscherer, G.; Voss, J. High affinity molecules disrupting Grb2 protein complexes as a therapeutic strategy for chronic myelogenous leukaemia. Leuk. Lymphoma 2003, 44, $411-427$.

(5) Burke, T. R., Jr.; Gao, Y.; Yao, Z.-J. In Biomedical Chemistry: Applying Chemical Principles to the Understanding and Treatment of Disease, 1st ed.; Torrence, P. R., Ed.; John Wiley \& Sons: New York, 2000; pp 189-210.

(6) Burke, T. R., Jr.; Yao, Z.-J.; Liu, D.-G.; Voigt, J.; Gao, Y. Phosphoryltyrosyl mimetics in the design of peptide-based signal transduction inhibitors. Biopolymers 2001, 60, 32-44.

(7) Burke, T. R., Jr.; Luo, J.; Yao, Z.-J.; Gao, Y.; Milne, G. W. A.; Guo, R.; Voigt, J. H.; King, C. R.; Yang, D. Monocarboxylic phosphotyrosyl mimetics in the design of Grb2 SH2 domain inhibitors. Bioorg. Med. Chem. Lett. 1999, 9, 347-352.

(8) Beaulieu, P. L.; Cameron, D. R.; Ferland, J. M.; Gauthier, J.; Ghiro, E.; Gillard, J.; Gorys, V.; Poirier, M.; Rancourt, J.; Wernic, D.; LlinasBrunet, M.; Betageri, R.; Cardozo, M.; Hickey, E. R.; Ingraham, R.; Jakes, S.; Kabcenell, A.; Kirrane, T.; Lukas, S.; Patel, U.; Proudfoot, J.; Sharma, R.; Tong, L.; Moss, N. Ligands for the tyrosine kinase p56 $6^{\text {lck }} \mathrm{SH} 2$ domain: Discovery of potent dipeptide derivatives with monocharged, nonhydrolyzable phosphate replacements. J. Med. Chem. 1999, 42, 1757-1766.

(9) Grucza, R. A.; Bradshaw, J. M.; Futterer, K.; Waksman, G. SH2 domains: From structure to energetics, a dual approach to the study of structure-function relationships. Med. Res. Rev. 1999, $19,273-293$.

(10) Shi, Z.-D.; Lee, K.; Liu, H.; Zhang, M.; Roberts, L. R.; Worthy, K. M.; Fivash, M. J.; Fisher, R. J.; Yang, D.; Burke, T. R. A novel macrocyclic tetrapeptide mimetic that exhibits low-picomolar Grb2 SH2 domain-binding affinity. Biochem. Biophys. Res. Commun. 2003, 310, 378-383.

(11) Shi, Z.-D.; Lee, K.; Wei, C.-Q.; Roberts, L. R.; Worthy, K. M.; Fisher, R. J.; Burke, T. R., Jr. Synthesis of a 5-methylindolylcontaining macrocycle that displays ultrapotent Grb2 $\mathrm{SH} 2$ domain-binding affinity. J. Med. Chem. 2004, 47, 788-791.
(12) Wei, C.-Q.; Gao, Y.; Lee, K.; Guo, R.; Li, B.; Zhang, M.; Yang, D.; Burke, T. R., Jr. Macrocyclization in the design of Grb2 SH2 domain-binding ligands exhibiting high potency in whole cell systems. J. Med. Chem. 2003, 46, 244-254.

(13) Shi, Z.-D.; Wei, C.-Q.; Lee, K.; Liu, H.; Zhang, M.; Araki, T.; Roberts, L. R.; Worthy, K. M.; Fisher, R. J.; Neel, B. G.; Kelley, J. A.; Yang, D.; Burke, T. R., Jr. Macrocyclization in the design of non-phosphorus-containing Grb2 SH2 domain-binding ligands. J. Med. Chem. 2004, 47 (8), 2166-2169.

(14) Available from Sigma-Aldrich Chemical Corp.

(15) Scholl, M.; Ding, S.; Lee, C. W.; Grubbs, R. H. Synthesis and activity of a new generation of ruthenium-based olefin metathesis catalysts coordinated with 1,3-dimesityl-4,5-dihydroimidazol-2-ylidene ligands. Org. Lett. 1999, 1, 953-956.

(16) Wei, C.-Q.; Li, B.; Guo, R.; Yang, D.; Burke, T. R., Jr. Development of a phosphatase-stable phosphotyrosyl mimetic suitably protected for the synthesis of high affinity Grb2 SH2 domainbinding ligands. Bioorg. Med. Chem. Lett. 2002, 12, 2781-2784.

(17) Gao, Y.; Wei, C.-Q.; Burke, T. R., Jr. Olefin metathesis in the design and synthesis of a globally constrained Grb2 SH2 domain inhibitor. Org. Lett. 2001, 3, 1617-1620.

(18) Soi, A.; Pfieiffer, J.; Jauch, J.; Schuring, V. Synthesis of chiral calix $[n]$ arenes. Part 2: Synthesis of new chiral calix $[n]$ arenes based on ( $p$-hydroxy-phenyl)-methone. Tetrahedron: Asymmetry 1999, 10, 177-182.

(19) Boyd, E. A.; Regan, A. C.; James, K. Synthesis of gama-ketosubstituted phosphinic acids from bis(trimethylsilyl)phosphonie and alpha,beta-unsaturated ketones. Tetrahedron Lett. 1992, 33 813-816.

(20) Boyd, E. A.; Regan, A. C.; James, K. Synthesis of alkylphosphinic acids from silyl phosphonites and alkyl halides. Tetrahedron Lett. 1994, 35, 4223-4226.

(21) Garcia-Echeverria, C.; Stamm, C.; Wille, R.; Arz, D.; Gay, B. Biotinylated phosphotyrosine containing peptides: a valuable tool for studies on phosphopeptide interactions with $\mathrm{SH} 2$ and PTB domains. Lett. Pept. Sci. 1997, 4, 49-53.

(22) Shi, Z.-D.; Karki, R. G.; Oishi, S.; Worthy, K. M.; Bindu, L. K. Dharmawardana, P. G.; Nicklaus, M. C.; Bottaro, D. P.; Fisher, R. J.; Burke, T. R., Jr. Utilization of a nitrobenzoxadiazole (NBD) fluorophore in the design of a Grb2 SH2 domain-binding peptide mimetic. Bioorg. Med. Chem. Lett. 2005, 15, 1385-1388.

(23) Oishi, S.; Karki, R. G.; Shi, Z.-D.; Worthy, K. M.; Bindu, L.; Chertov, O.; Esposito, D.; Frank, P.; Gillette, W. K.; Maderia, M. A.; Hartley, J.; Nicklaus, M. C.; Barchi, J. J., Jr.; Fisher, R. J.; Burke, T. R., Jr. Evaluation of macrocyclic Grb2 SH2 domainbinding peptide mimetics prepared by ring-closing metathesis of C-terminal allylglycines with an $\mathrm{N}$-terminal $\beta$-vinyl-substituted phosphotyrosyl mimetic. Bioorg. Med. Chem. 2005, 13, $2431-2438$

(24) van Kempen, G. M.; van Vliet, L. J. Mean and variance of the ratio estimators used in fluorescence ratio imaging. Cytometry 2000, 39, 300-305.

(25) Shi, Z.-D.; Karki, R. G.; Worthy, K. M.; Bindu, L. K.; Fisher, R. J.; Burke, T. R., Jr. Utilization of a common pathway for the synthesis of high affinity macrocyclic Grb2 SH2 domain-binding peptide mimetics that differ in the stereochemistry of one ring junction. Chem. Biodiversity 2005, 2, 445-456.

(26) Note: Differences between the current affinity of $\mathbf{4 h}$ and the previously reported value (ref $10, K_{\mathrm{D}}=93 \mathrm{pM}$ ) are discussed in ref 23.

(27) Furet, P.; Caravatti, G.; Denholm, A. A.; Faessler, A.; Fretz, H.; Garcia-Escheverria, C.; Gay, B.; Irving, E.; Press, N. J.; Rahuel, J.; Schoepfer, J.; Walker, C. V. Structure-based design and synthesis of phosphinate isosteres of phosphotyrosine for incorporation into Grb2-SH2 domain inhibitors. Part 1. Bioorg. Med. Chem. Lett. 2000, 10, 2337-2341.

(28) Smyth, M. S.; Ford, H.; Burke, T. R., Jr. A general-method for the preparation of benzylic $\alpha, \alpha$-difluorophosphonic acidsnonhydrolyzable mimetics of phosphotyrosine. Tetrahedron Lett 1992, 33, 4137-4140.

(29) Burke, T. R., Jr.; Smyth, M. S.; Otaka, A.; Nomizu, M.; Roller P. P.; Wolf, G.; Case, R.; Shoelson, S. E. Nonhydrolyzable phosphotyrosyl mimetics for the preparation of phosphataseresistant SH2 domain inhibitors. Biochemistry 1994, 33, 64906494.

(30) Bradshaw, J. M.; Mitaxov, V.; Waksman, G. Investigation of phosphotyrosine recognition by the $\mathrm{SH} 2$ domain of the Src kinase. J. Mol. Biol. 1999, 293, 971-985.

(31) Song, Y.-L.; Roller, P. P.; Longa, Y.-Q. Development of L-3aminotyrosine suitably protected for the synthesis of a novel nonphosphorylated hexapeptide with low-nanomolar Grb2-SH2 domain-binding affinity. Bioorg. Med. Chem. Lett. 2004, 14, $3205-3208$

JM050059M 